\title{
ASSESSMENT OF THE QUALITY OF LIFE OF A GROUP OF SUBJECTS AGED 65 AND OVER (MOROCCO)
}

\author{
Abdellatif BAALI (1), Hakima AMOR (1), Raja ZAKARIA (1), Noureddine EL KHOUDRI (2), \\ Nadia FATHI (3), Nadia EL KADMIRI (3)
}

DOI: $\underline{\text { htp: }: / / d o i . o r g / 10.26758 / 11.1 .11 ~}$

(1) Laboratory of Human Ecology, Faculty of Sciences Semlalia, "Cadi Ayyad" University, Marrakesh, Morocco; E-mails: abdellatifbaali@hotmail.com; amor@uca.ac.ma; rajazakaria1@gmail.com

(2) Higher Institute of Health Sciences, "Hassan I" University, Settat, Morocco; E-mail: noureddinebio@hotmail.com

(3) Molecular engineering, valuation and environment team, Multidisciplinary Faculty, "Ibn Zohr" University, Taroudant, Morocco; E-mails: nadia.fathi@edu.uiz.ac.ma; n.elkadmiri@uiz.ac.ma

Address correspondence to: Abdellatif Baali, Laboratory of Human Ecology, Faculty of Sciences Semlalia, Cadi Ayyad University, Bd. My Abdallah, BP 2390, Marrakesh, Morocco. Ph.: 212661613396; E-mail: abdellatifbaali@hotmail.com

\begin{abstract}
Objective. The aim of this study was to assess the health related quality of life of elderly Moroccans living at home as well as determining the factors that influence it.

Material and methods. The data was gathered through a questionnaire survey conducted between 2017 and 2018. Age, gender, level of education, socio-professional activity, morbidity and perception of old age were chosen as variables, and the LEIPAD scale was used to evaluate the respondent's quality of life, French version.

Results. This study included 520 subjects aged 65 and above ( 277 men and 243 women). The average age was 71.2 years, and $60.8 \%$ of them were illiterate, $22.3 \%$ employed, $25.0 \%$ retired, and $52.7 \%$ have never worked. In addition, $57.9 \%$ of participants had at least one chronic illness and $42.9 \%$ had a pessimistic attitude toward old age. Overall, the surveyed subjects' quality of life was adequate and satisfactory. The main ratings for the areas involving "taking care of oneself" and "depressionanxiety" were the lowest (23.7 and 28.6). On the other hand, the "sexual functioning" area was the most affected (score=73.7), thus impacting the participants' quality of life. Furthermore, sociodemographic characteristics proved to have a negative impact on the participants' quality of life. The highest average test scores were reported by women, the oldest subjects (>-75 years), subjects with low levels of education, without professions and retirees, suffering from chronic diseases and those who negatively perceived the old age, which showed a relatively impaired quality of life.

Conclusions. The majority of the surveyed people had a good quality of life. Nevertheless, providing adequate treatment for the most disadvantaged elderly people could improve their quality of life and help them reach the old age in good health.
\end{abstract}

Keywords: quality of life, elderly, test LEIPAD, Morocco. 


\section{Introduction}

Globally, the number of people aged 65 and over will reach 1.5 billion by 2050, up from 703 million in 2019. The proportion of people in this age group has increased from 6\% in 1990 to $9 \%$ in 2019 and will increase further to $16 \%$ in 2050, making one in every six people 65 years or older (United Nations, 2019). Due to the impact of the techno-cultural environment and the significant widespread medicalization, the majority of individuals were able to reach adulthood and, subsequently, the old age. Nevertheless, aging is associated with the deterioration of elderly health, sensory condition, nutritional state, and changes in their perception of life (progressive or brutal isolation, lack of social contacts, confinement at home, etc.), ranging from material, physical or financial incapacity (fragility, risk of dependence at the end of life...) to psychophysiological problems (anxiety, depression, etc.). However, as people grow older, all of these factors may have a negative effect on their quality of life. As a result, as the population ages, new issues emerge, such as the rising prevalence of chronic diseases and physical disorders, which particularly affect the elders (Monod-Zorzi, Seematter-Bagnoud, Büla, Pellegrini, \& Jaccard, 2007; Lalive d'Epinay, Guilley, Guillet, \& Spini, 2008).

Quality of life is defined as an "individuals' perception of their position in life in the context of the culture and value systems in which they live, and in relation to their goals, expectations, standards and concerns" (World Health Organization (WHO), 1999). It is a very broad concept influenced in a complex way by the participant's physical health, psychological state, level of independence, active participation, social image, social support system, social relationships as well as his or her relationship to the essential elements of his or her environment. Furthermore, the quality of life would depend on the gender of the individual, his or her age, living conditions, family, entourage, socio-economic level and state of health (chronic illnesses, health behaviors, etc.) (Compagnone, Van, \& Bouisson, 2007; Rada, 2020). Standardized and validated questionnaires would allow a precise and a reliable assessment of the quality of life linked to the health of the elderly individuals. The LEIPAD test (acronym resulting from the universities involved in creating it: Padua and Brescia - Italy, Leiden - the Netherlands, and Helsinki - Finland) is one of the instruments that can be used to identify seven dimensions of the individual's state of health: the physical function, level of independence, anxiety and depression, cognitive functioning, social life, sexual life and life satisfaction.

In addition, Morocco's population, like the rest of the world, is rapidly aging: people aged 60 and over accounted for $8 \%$ in $2004,10.5 \%$ in 2018, and $11.5 \%$ in 2020. In addition, by 2030 , the ratio will reach $15.4 \%$, and almost a quarter of Moroccans (23.2\%) will belong to this age group. Furthermore, life expectancy at birth is expected to increase from 76.1 years in 2017 (71 years in 2004) to 80.4 years in 2050 (Haut-Commissariat au Plan (HCP) 2006; 2017) [High Commission for Planning]. In the face of these positive trends, improving the quality of life of the elderly is an increasingly important challenge for the Moroccan country as well as for the responsible political and health services, especially from this age group when the social security system is still fragile and remote. In addition, in most cases, part or all of the care of the elderly is still mainly the responsibility of the family, especially the children. Thus, the objective of this study was to evaluate the quality of life of a group of individuals aged over 65 years old and living at home in Morocco using a specific and validated self-administered scale, in order to detect the dimensions of the LEIPAD test that affected the quality of life of these subjects and finally, to grasp the associated socio-demographic factors.

\section{Material and methods}

The data for this study came from a survey conducted at the Marrakesh City Health Center from 2017 to 2018, and the subjects were 520 elderly people over 65 years old. The subjects under 
investigation were randomly selected during their visits to these health centers for consultation, medical treatment or accompanying their family members. The data was obtained through direct interviews and questionnaires on the subject. This information was collected anonymously, respecting the confidentiality; the interviews were conducted only with the subjects who had approved it in advance. The selected variables were: gender, age, education level, social professional activities, health status (chronic diseases) and perceptions of old age, and were evaluated by the following questions: "For you, what is like getting old?" to which there were two types of answer (Yes/No). The quality of life of these subjects was assessed by the LEIPAD test (De Leo et al., 1998), French version (Jalenques et al., 2013). This is a multi-dimensional instrument composed of 31 items, each of them containing 2 to 6 items: physical function (understand the physical condition of the elderly), self-care (the ability to carry out daily activities by oneself), depression-anxiety (right anxiety assessment and perception of depression), cognitive function (attention, confusion, memory problems), social function (individual integration and satisfaction in society), sexual function (interest and sexual ability/activities) and life satisfaction (satisfaction with the standard of living and the financial situation). The score for each item is divided into a 4-point Likert scale, ranging from 0 (better quality of life) to 3 (very poor quality of life) (Table 1). Therefore, high scores reflect changes in the personal quality of life. A single total score is obtained by adding the scores of different items, and the total score of each of the seven categories is converted linearly on a scale from 0 to 100 .

The data was collected and statistically processed through SPSS PC 18. Qualitative variables were expressed in quantity and percentage, while the quantitative variables were expressed in means and standard deviation. The comparison between groups was performed by a Chi-square test for qualitative variables, and the non-parametric test, Mann-Whitney and Kruskal-Wallis test for quantitative variables. The significance threshold was set to $5 \%$.

\section{Results}

\section{Socio-demographic profile of the studied group}

The results are shown in Table 1 . The sample studied included 520 elderly people aged 65 and over living at home, including 277 men (53.3\%) and 243 women (46.7\%). The average age was 71.2 years ( $\sigma=6.5$; range: $65-96$ years), of which $65-74$ years old accounted for the highest proportion, $75.8 \%$, while older people or those over 4 years old $(>=80$ years old) represented only $6.3 \%$. At the time of the survey, more than half of the participants $(58.5 \%)$ lived with their partners, while $6.5 \%$ were single, $6.7 \%$ were divorced and $28.3 \%$ were widowed. In terms of education level, $60.8 \%$ of the people in this sample were illiterate, $17.9 \%$ were in elementary schools, $14.2 \%$ were in middle schools, and $7.1 \%$ were in higher education. As far as the social professional activities were concerned during the survey, only $22.3 \%$ of the participants reported that they were still working at the time of the survey, $25.0 \%$ had retired, and $52.7 \%$ had never worked or had no occupation. Among retirees, only $19.0 \%$ received pensions. In addition, $57.9 \%$ of participants reported having at least one chronic disease. Among them, 33.7\% were suffering from one disease, 13.3\% were suffering from 2 diseases, 9.0\% were suffering from 3 diseases, and 1.9\% suffering from 4 diseases. Diabetes and hypertension were the two most common chronic diseases, at $26.3 \%$ and $24.4 \%$, respectively, followed by rheumatic diseases $(12.9 \%)$, cardiovascular diseases $(8.1 \%)$ and respiratory diseases $(4.2 \%)$. The prevalence of other reported diseases was relatively low (frequency between $0.2 \%$ and $2.5 \%$ ). After medical diagnosis, these diseases were identified in $97.7 \%$ of cases. The proportion of individuals enjoying medical insurance was $56.3 \%$, of which $28.6 \%$ of the Medical Assistance Plan (RAMed) in Morocco covering individuals socially disadvantaged. Finally, among the 326 participants who answered to the questionnaire on feelings of old age, $57.1 \%$ of them had positive feelings about old age. 


\section{Table 1}

Socio-demographic profile of the study group

\begin{tabular}{lccc}
\hline Variables & Modalities & Frequency & $\%$ \\
\hline \multirow{2}{*}{ Gender } & Men & 277 & 53.3 \\
& Women & 243 & 46.7 \\
Age groups (in years) & $65-74$ & 394 & 75.8 \\
& $75-84$ & 93 & 17.9 \\
Level of study & $>=85$ & 33 & 6.3 \\
& No & 316 & 60.8 \\
& Primary & 93 & 17.9 \\
Socio-professional activity & Secondary and & 111 & 21.3 \\
& more & 274 & 52.7 \\
Chronic diseases & Without profession & 116 & 22.3 \\
& Active & 130 & 25.0 \\
Old age perception & Retired & 301 & 57.9 \\
& Yes & 219 & 42.1 \\
& No & 186 & 57.1 \\
& Positive & 140 & 42.9 \\
\hline
\end{tabular}

\section{Quality of life}

The average LEIPAD test score of the elderly participants in the study was $33.7(=17.1)$. Cronbach's alpha value was 0.94 . In order of importance, the average scores on each dimension of the test were as follows: sexual function (73.7 \pm 27.1$)$, physical (43.9 \pm 25.3$)$, social (37.6 \pm 20.9$)$, life satisfaction (36.7 \pm 22.1$)$, and cognitive function (33.1 \pm 24.1$)$, depression and anxiety $(28.6 \pm 24.8)$ and finally self-care $(23.7 \pm 25.1)$. The propositions of the scores of the responses to different test items are given in Table 2. For the sexual function that had the greatest impact on the quality of life of the study subjects, the ratio of individuals who were not interested in sex and completely abstain from sexual relations range between $46.7 \%$ and $46.5 \%$. In terms of function, the perception of the subject's health status seemed to affect the score of this dimension. Among the participants, $52.1 \%$ considered their physical condition not good (17.1 is extremely poor), and other items were related to sleep problems, feeling tired, etc., more than half of the participants were in a positive state. As for other categories, regardless of the category, the percentage of individuals in good condition was very high. In fact, participants usually had a positive view of their social life. They were satisfied with their social relationships with their families and within the communities, their financial situation, current living conditions, very optimistic for their future, mnemonic, attentive, neither anxious, nor depressed and feeling that they had no difficulty in carrying out their daily tasks independently (climbing stairs, eating, getting dressed, bathing).

\section{Quality of life and profile of the studied group}

Table 3 shows the results of the study on the relationship between the average score of the LEIPAD exam and its components, as well as the socio-demographic characteristics of the participants. The quality of life of the participants was statistically calculated, sorted by importance, 
incidence, age, gender, literacy and awareness of old age. The participants suffering from chronic diseases were the oldest ones, while also having a low level of education and a negative perception of old age, thus having the highest average scores, i.e. their quality of life was relatively impaired. For other variables, there was no correlation between the "Social Functioning" scale and the satisfaction with life between men and women, as well as social professional activities, feelings of old age and the "Depression and Anxiety" scale. Finally, the scales of "social function" and "sexual function" seemed to had no connection with feelings of old age.

\section{Table 2}

Scores (in \%) of the subjects' responses to the different items of the LEIPAD test

\begin{tabular}{|c|c|c|c|c|}
\hline \multirow[t]{2}{*}{ Scales and items } & \multicolumn{4}{|c|}{ Scores } \\
\hline & 0 & 1 & 2 & 3 \\
\hline \multicolumn{5}{|l|}{ Physical functioning } \\
\hline 1-How would you rate your overall physical health? & 8.9 & 38.9 & 36.5 & 15.8 \\
\hline 6-Do you have sleep problems? & 29.8 & 39.0 & 23.1 & 8.0 \\
\hline 7-Do you feel tired, without energy? & 16.3 & 41.4 & 28.9 & 13.4 \\
\hline 9-Are you able to accomplish your usual tasks either at home, at work, or elsewhere? & 31.5 & 26.4 & 25.9 & 16.3 \\
\hline $\begin{array}{l}\text { 12-How much do your physical health problems (if any) stand in the way of doing the } \\
\text { things you want to do? }\end{array}$ & 32.9 & 35.8 & 17.1 & 14.2 \\
\hline \multicolumn{5}{|l|}{ Self-care } \\
\hline 2-Are you able to get up and down the stairs without help? & 46.9 & 33.7 & 12.5 & 6.8 \\
\hline 3-Are you able to dress all by yourself? & 69.2 & 19.7 & 7.5 & 3.6 \\
\hline 4-Are you able to eat by yourself? & 81.5 & 12.5 & 4.1 & 1.9 \\
\hline 5-Are you able to bathe or take a shower by yourself? & 56.3 & 22.1 & 16.8 & 4.8 \\
\hline $10-$ Can you shop all by yourself? & 46.1 & 23.6 & 10.6 & 19.7 \\
\hline 11-Can you travel by public transportation? & 45.4 & 21.7 & 13.7 & 19.2 \\
\hline \multicolumn{5}{|l|}{ Cognitive functioning } \\
\hline 8-Do you have difficulties concentrating? & 33.4 & 39.4 & 20.9 & 6.3 \\
\hline $\begin{array}{l}\text { 13-How often, would you say, does it happen that you are not able to think clearly or that } \\
\text { you are confused? }\end{array}$ & 29.8 & 35.6 & 25.7 & 8.9 \\
\hline $\begin{array}{l}\text { 14-How much do your problems with thinking (if any) stand in the way of doing the things } \\
\text { you want to do? }\end{array}$ & 38.7 & 38.2 & 15.8 & 7.4 \\
\hline $15-$ How good is your memory? & 19.7 & 50.0 & 19.5 & 10.8 \\
\hline 16-How much do your memory problems (if any) stand in the way of doing the things you & 56.5 & 28.1 & 11.1 & 4.3 \\
\hline
\end{tabular}
want to do?

Depression and anxiety

17-Taking everything in consideration, how anxious do you feel?

$26.5 \quad 41.8 \quad 21.1 \quad 10.6$

18-How much do your feelings of anxiety (if any) stand in the way of doing the things you

want to do?

$\begin{array}{llll}42.5 & 34.8 & 17.6 & 5.1\end{array}$

19-Taking everything in consideration, how depressed (blue) do you feel at present? $\quad \begin{array}{lllll}47.8 & 34.8 & 14.2 & 3.3\end{array}$

20-How much do your depressed feelings (if any) stand in the way of doing the things you

want to do?

$\begin{array}{llll}54.6 & 31.0 & 11.1 & 3.3\end{array}$

\section{Social functioning}

21-How satisfied are you with your social ties or relationships?

22-Do you feel emotionally satisfied in your relationships with other people?

23-Is there someone to talk to about personal affairs when you want to?

Sexual functioning

24-Are you interested in sex?

25-How often do you have sexual contact?

Life satisfaction

26-How satisfied are you with your ability to manage your hobbies or recreational activities?

27-How satisfied are you with your financial situation?

28-Do you feel you cannot afford the standard of living you would like?

$\begin{array}{llll}40.4 & 48.3 & 9.8 & 1.5\end{array}$

$\begin{array}{llll}13.9 & 42.8 & 26.4 & 17.0\end{array}$

$\begin{array}{llll}39.2 & 25.2 & 21.2 & 14.4\end{array}$

$\begin{array}{llll}5.8 & 15.6 & 31.2 & 47.4\end{array}$

$\begin{array}{llll}3.3 & 16.3 & 31.5 & 49.0\end{array}$

\begin{tabular}{cccc}
\hline 21.4 & 41.3 & 25.2 & 12.2 \\
22.4 & 40.8 & 27.4 & 9.4 \\
39.7 & 34.6 & 18.0 & 7.7
\end{tabular}




\begin{tabular}{|c|c|c|c|c|}
\hline \multirow[t]{2}{*}{ Scales and items } & \multicolumn{4}{|c|}{ Scores } \\
\hline & 0 & 1 & 2 & 3 \\
\hline 29-How satisfied are you with your life at present when compared to the past? & 22.6 & 33.9 & 28.3 & 15.2 \\
\hline 30-Taking everything in consideration, how would you expect things will go in the future? & 19.9 & 57.5 & 18.0 & 4.6 \\
\hline $\begin{array}{l}31-\text { How much do your expectations of the future stand in the way of doing or initiating the } \\
\text { things you want to do (want)? }\end{array}$ & 54.8 & 31.7 & 10.6 & 2.9 \\
\hline
\end{tabular}

\section{Table 3}

Average scores of the LEIPAD test and each of its scales and socio-demographic profile of the studied group

\begin{tabular}{|c|c|c|c|c|c|c|c|c|c|}
\hline Variables & Modalities & LEIPAD & $\mathrm{PF}$ & $\mathrm{SC}$ & DA & $\mathrm{CF}$ & SF & $\mathrm{XF}$ & LV \\
\hline \multirow{3}{*}{ Gender } & Men & $29.8 \pm 15.5$ & $39.5 \pm 24.4$ & $18.3 \pm 22.3$ & $24.8 \pm 22.6$ & $28.6 \pm 22.3$ & $36.8 \pm 20.3$ & $62.4 \pm 27.0$ & $34.9 \pm 21.1$ \\
\hline & & $38.1 \pm 17.8$ & $48.9 \pm 25.6$ & $29.9 \pm 26.8$ & & $38.2 \pm 25.0$ & $38.6 \pm 21.5$ & $86.6 \pm 20.8$ & $38.7 \pm 23.0$ \\
\hline & $U$ test & $5.4 * * *$ & $4.2 * * *$ & $5.4 * * *$ & $3.5 * * *$ & $4.4 * * *$ & $1.0 \mathrm{~ns}$ & $10.5 * * *$ & $1.7 n s$ \\
\hline \multirow{4}{*}{$\begin{array}{l}\text { Age } \\
\text { groups } \\
\text { (in years) }\end{array}$} & $65-74$ & $30.3 \pm 15.3$ & $38.4 \pm 22.1$ & $18.1 \pm 21.1$ & $27.1 \pm 24.1$ & $30.0 \pm 21.7$ & $35.5 \pm 21.0$ & $69.2 \pm 27.4$ & $34.6 \pm 21.7$ \\
\hline & $75-84$ & $43.5 \pm 18.2$ & $60.5 \pm 27.7$ & $39.2 \pm 28.0$ & $34.1 \pm 26.5$ & $42.0 \pm 29.2$ & $44.8 \pm 20.0$ & $86.4 \pm 22.1$ & $43.0 \pm 2$ \\
\hline & $>=85$ & $45.9 \pm 18.2$ & $63.8 \pm 24.9$ & $46.8 \pm 30.3$ & $32.3 \pm 25.7$ & & $42.8 \pm 16.9$ & $90.9 \pm 16.7$ & $44.3 \pm$ \\
\hline & H test & $52.8^{* * *}$ & $67.5 * * *$ & $67.2 * * *$ & $6.6^{*}$ & $19.2 * * *$ & $15.9 * * *$ & $49.9 * * *$ & $15.4 * * *$ \\
\hline \multirow{4}{*}{$\begin{array}{l}\text { Level of } \\
\text { study }\end{array}$} & No & & $47.6 \pm 26.4$ & $27.6 \pm 26.4$ & 25.3 & $5 \pm 25.2$ & $39.3 \pm 20.6$ & \pm 23.9 & $39.9 \pm 22.5$ \\
\hline & & & $41.7 \pm 24.9$ & $19.1 \pm 24.4$ & $30.6 \pm$ & $28.5 \pm 22.0$ & $43.8 \pm 20.4$ & $65.9 \pm 28.0$ & 19.8 \\
\hline & $S$ & $25.7 \pm 12.5$ & $35.3 \pm 19.8$ & $16.6 \pm 19.4$ & $22.2 \pm 20.1$ & $27.1 \pm 20.6$ & $27.6 \pm 18.8$ & $60.4 \pm 28.5$ & $25.2 \pm 18.6$ \\
\hline & H te & & $17.2 * * *$ & $20.5 * * *$ & $8.0 *$ & $14.7 * * *$ & $37.3 * * *$ & $53.8 * * *$ & $38.0 * * *$ \\
\hline \multirow{4}{*}{$\begin{array}{l}\text { Socio- } \\
\text { professional } \\
\text { activity }\end{array}$} & $\begin{array}{l}\text { Witho } \\
\text { profes }\end{array}$ & $37.0 \pm 17.7$ & $47.0 \pm 26.2$ & $27.3 \pm 26.8$ & $30.9 \pm 26.5$ & $35.7 \pm 25.0$ & $40.3 \pm 21.3$ & $84.2 \pm 22.0$ & $40.2 \pm 22.0$ \\
\hline & Active & $31.5 \pm 17.8$ & $41.4 \pm 25.3$ & $18.6 \pm 23.8$ & $28.5 \pm 24.2$ & $32.5 \pm 24.2$ & $36.0 \pm 21.6$ & $61.4 \pm 28.5$ & $37.2 \pm 23.2$ \\
\hline & Retirees & 28.7 & $39.7 \pm 22.7$ & $20.7 \pm 21.3$ & $24.1 \pm 20.6$ & $28.1 \pm 21.1$ & $33.5 \pm 18.7$ & $62.4 \pm 26.8$ & $28.8 \pm 19.1$ \\
\hline & $H$ test & $19.6 * * *$ & $7.7^{*}$ & $12.5 * *$ & $4.0 \mathrm{~ns}$ & $7.7^{*}$ & $10.6 * *$ & $91.4 * * *$ & $24.6 * * *$ \\
\hline \multirow{3}{*}{$\begin{array}{l}\text { Chronic } \\
\text { diseases }\end{array}$} & Yes & $40.5 \pm 16.8$ & $56.0 \pm 23.6$ & $33.1 \pm 26.8$ & $36.4 \pm 24.7$ & $40.8 \pm 24.1$ & $40.3 \pm 19.1$ & $77.9 \pm 26.1$ & $41.0 \pm 22.4$ \\
\hline & No & $24.3 \pm 12.4$ & $27.4 \pm 17.0$ & $10.9 \pm 15.3$ & $18.0 \pm 20.5$ & $22.5 \pm 19.6$ & $33.9 \pm 22.7$ & $67.9 \pm 27.5$ & $30.7 \pm 20.1$ \\
\hline & $U$ test & & $13.0 * * *$ & $10.5 * * *$ & $9.0 * * *$ & $8.6^{* * *}$ & $3.3 * * *$ & & \\
\hline \multirow{3}{*}{$\begin{array}{l}\text { Old age } \\
\text { perception }\end{array}$} & & $34.0 \pm 16.6$ & $45.1 \pm 25.4$ & $23.6 \pm 24.9$ & $31.3 \pm 25.2$ & $33.9 \pm 22.7$ & $39.8 \pm 20.8$ & $72.0 \pm 28.3$ & $34.6 \pm 21.2$ \\
\hline & Negative & $41.0 \pm 19.2$ & $53.2 \pm 27.4$ & $32.1 \pm 28.8$ & $36.0 \pm 27.5$ & $44.0 \pm 25.2$ & $41.5 \pm 20.6$ & $75.2 \pm 27.6$ & $44.9 \pm 24.5$ \\
\hline & $U$ test & $3.4 * * *$ & $2.7 * * *$ & $2.6^{* *}$ & $1.5 \mathrm{~ns}$ & $3.5 * * *$ & $0.8 n s$ & $1.1 n s$ & $3.9 * * *$ \\
\hline
\end{tabular}

$\mathrm{PF}=$ Physical functioning, $\mathrm{SC}=$ Self-care, $\mathrm{DA}=$ Depression and anxiety, $\mathrm{CF}=$ Cognitive functioning, $\mathrm{SF}=$ Social functioning, $\mathrm{SxF}=$ Sexual functioning, $\mathrm{LF}=\mathrm{Life}$ satisfaction. $\mathrm{U}$ and $\mathrm{H}$ test=Mann-Withney and Kruskal-Wallis test, respectively; $*=\mathrm{p}<0.05 ; * *=\mathrm{p}<0.01 ; * * *=\mathrm{p}<0.001$. 


\section{Discussions}

The study included 520 Moroccans 65 years and older, including 277 men and 243 women. The average age was 72.2 years, and there were very few subjects $(6.3 \%)$ aged 80 years and over, while the number of subjects in the $65-74$ age group is $75.8 \%$. This fact can be attributed to the difference in mortality and the decrease in life expectancy with age; nationwide, the life expectancy at birth in 2018 was 76.1 years (HCP, 2017). Most of the study subjects lived with their families (92.3\%), and more than half (58.5\%) lived with their husbands and wives. Family life enables social connections and solidarity and mutual assistance between family members, thereby helping to improve the quality of life of the elderly. Compared with the national level of 2012, the literacy rate of the surveyed samples (37.7\%) was very high, i.e. 28\% (Observatoire National du Développemet Humain $(\mathrm{ONDH})$, 2015) [National Observatory for Human Development]. This significant improvement is the result of the progress made by the Moroccan country to improve the educational level of all generations, and it is also the result of the large number of respondents in the sample belonging to the 50s generation (65-69 years old) when the population gradually began to go to school during the independence period. As for social professional activities, only $22 \%$ of the participants were active at the time of the survey, which was relatively low compared to the 2012 study conducted by Baali et al. (2012) in the city of Marrakesh. However, this study included participants of 60 years and older. On the other hand, $25 \%$ of the participants retired and more than half $(52.7 \%)$ had no social activities. In fact, a large number of the surveyed elderly people have a low percentage of participation in social and professional activities, which guarantees their retirement pensions. This is due to the high percentage of women who have never participated in social and professional activities, $87.7 \%$, as opposed to men, who account for only $22 \%$. Therefore, the proportion of people receiving pensions was only $19.0 \%$, a rate that was relatively low in 2017, among people aged 60 and over, i.e. (24.5\%) (Autorité de Contrôle des Assurances et de la Prévoyance Sociale (ACAPS), 2017) [Insurance and Social Welfare Control Authority].

In addition, like all elderly people, the percentage of individuals with chronic diseases was very high, and $57.9 \%$ of the surveyed participants reported having at least one chronic disease. Diabetes and hypertension both accounted for $50.7 \%$ of the recorded chronic diseases; these diseases were the most common diseases observed in a group of Moroccan participants, accounting for 34.1\% (the average age of the group was $64.3 \pm 21.6$ years) (Elkafssaoui et al., 2017). The proportion of individuals with chronic diseases recorded in our sample has increased along with the age; for the three surveyed age groups, $50.2 \%, 61.3 \%$ and $77.6 \%$ of people had at least one chronic disease. This result is consistent with research showing that aging increases the risk of chronic diseases (MonodZorzi et al., 2007; Lalive d'Epinay et al., 2008). This will require treatment of affected individuals because the treatment of these diseases is time-consuming and expensive. In addition, medical insurance covers only a small part of the population, accounting for 60\% (Agence Nationale de 1'Assurance Maladie (ANAM), 2016) [National Agency for Health Insurance]. This rate has increased since 2005 (25\%), thanks to the generalization of the medical assistant scheme (RAMED) since 2012. The surveyed sample with medical coverage rate $(56.3 \%)$ was relatively close to the national level, but the RAMED system sample accounts for more than half (27.7\%). Finally, $42.9 \%$ of the participants expressed negative opinions about old age; compared with $37.5 \%$ in 2012, this proportion is relatively high (Baali et al., 2012). This feeling does not seem to be related to age or incidence, but to the gender and education level of the participants. In fact, there were the women and those with a low level of education who had a negative perception of ageism. Perception of aging is considered one of the indicators of health and vulnerability: the more negative people's perceptions of aging, the easier it is for them to reach a worrying state of vulnerability (Bruin, Picavet, Nossikov, \& WHO Regional Office for Europe, 1996).

The quality of life of the participants seemed to be generally satisfying; the average LEIPAD score was very low, at 33.7 (LEIPAD scores range from 0 to 93). In fact, 25\% of participants scored 
greater than 43 (75th percentile), and only $10 \%$ of participants scored greater than 59 (90th percentile). The results showed that participants enjoyed greater autonomy, and very few of them had difficulties in completing daily tasks independently without the help of anyone else (climbing stairs, eating, dressing, bathing, etc.). Similarly, they were in a good mental health (very low average score for the "depression and anxiety" dimension was very low). However, diagnosing the elderly with depression and anxiety is still difficult (Thomas \& Hazif-Thomas, 2008). In addition, their cognitive function (mental ability, knowledge acquisition and memory) was satisfactory: the average score of this dimension was low, and the score was higher than $70 \%$ of the cognitive function (mental ability, knowledge acquisition and memory). The average score of this dimension was low, and more than $70 \%$ of the participants were in a positive state. This feature can be attributed to the predominance of the 65-74 age group in this sample (75.8\%). Moreover, they were doing quite well were more likely to reach the age of 75 .

As for the two variables "life satisfaction" and "social functioning", they reflected the extent to which the surveyed people were satisfied with the standard norms of their life in the community and their current financial situation as well as their perception of the future, which shows that the respect which is granted to the elderly by the community, as well as the solidarity and the socioculturally governed family ties are still strong and solid for them. These attitudes and behaviors will only have a positive impact on the individual's living conditions (providing daily needs, satisfactory living conditions, shopping and travel expenses, access to medical care, etc.) and will reduce their psychological deterioration. Nevertheless, the quality of life of the participants was affected by certain changes caused by the "sexual function" variable, while the changes caused by the "body function" variable were smaller. The average scores of these two variables were 73.3 and 43.9, respectively. As for physical function, it seemed that the self-perception regarding the health had had the greatest influence on the score of this variable. $47.8 \%$ of the participants thought they were in poor physical condition (including $9 \%$ in extremely poor physical condition). The actual health status of the participants made an important contribution to this self-assessment. In fact, $76.4 \%$ of participants with a chronic disease believed that their health was very poor (including $28.6 \%$ of people who were in poor physical condition), while only $18.8 \%$ of the participants (including 1, 4\% who were unwell) considered themselves to be unaffected ( $\chi 2$ to $3 \mathrm{ddl}=177.8 ; \mathrm{p}<0.001)$. Regarding other items in the scale (sleep problems, feelings of fatigue, completing daily tasks, health-related obstacles), most participants (over 55\%) had the lowest score (0 or 1), indicating a better quality of life. As for the "sexual functioning" scale, it is well known that problems related to sexual activity are frequently encountered by the elderly (Jalenques, Auclair, Rondepierre, Gerbaud, \& Tourtauchaux, 2015; Kharrat, Mersni, Guebsi, Ben Salah, \& Dziri, 2017). Many variables are believed to have an influence on the sexual life of elderly participants, such as: reproductive aging, hormone deficiency, related pathologies and their treatments (diabetes, hypertension), menopause, psychosocial factors, sexual desire disorders (Graziottin \& Leiblum, 2005; Grafeille, 2016).

In addition, the socio-cultural background may also be the reason for this result, because sexuality is still considered a taboo topic, especially among people of this age group, and even among unmarried elderly participants. However, the widowhood experienced by participants who lost their spouse had a significant impact on this ratio. Widows had an average score of 96.5, and married participants had an average score of 62.2 (average scores for divorced and single persons were 72.4 and 79.4). The latest work of Jalenques et al. (2015) and Kharrat et al. (2017), carried out on French and Tunisian participants aged 65 and above (Figure 1), also revealed the negative impact of the scale on the quality of life of the respondents. Finally, the average scores of the various scales obtained in the study are higher than those of the French counterparts (except for LS); difference which could be attributed to the obvious difference in the living conditions and caring conditions for the elderly participants studied compared to their French peers. There are obvious differences in living conditions and nursing conditions. On the other hand, the score registered for this research was much lower than that of the Tunisian group. The difference between the two groups of elderly participants with 
relatively similar socioeconomic levels was due to the fact that the average age of Tunisians (74.3 years) was higher than the average age of Moroccans (71.2 years), and the sample of Tunisians only included participants who have been interviewed during their hospitalization.

\section{Figure 1}

Average scores of the dimensions of the LEIPAD scale of the studied group, compared to those of their Tunisian and French counterparts

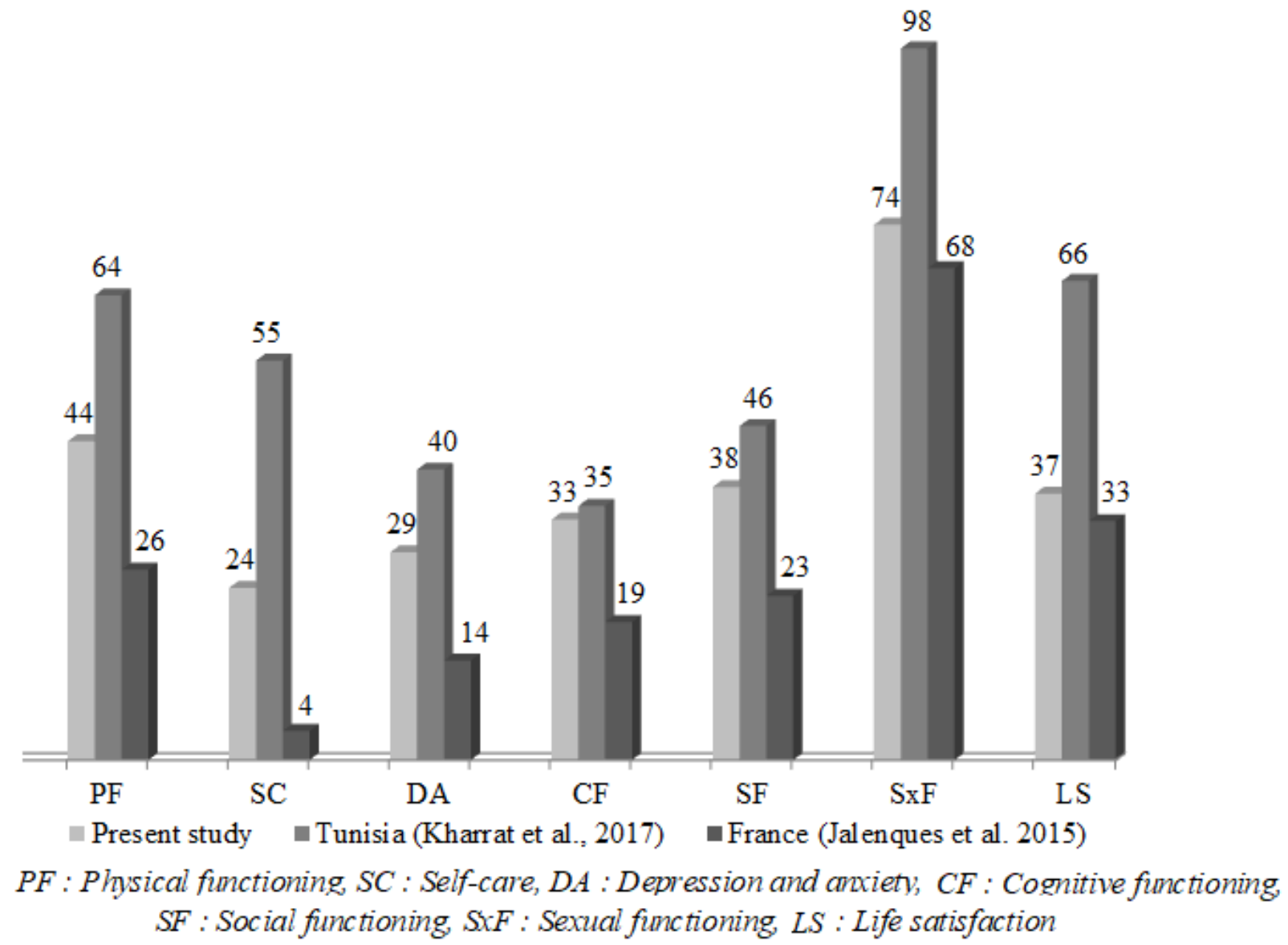

Furthermore, there is a clear relationship between the quality of life and its span and the socio-demographic characteristics of the studied sample (Table 3). These results indicate that women's quality of life seemed to be more impaired than men's, which could be attributed primarily to sexual functioning. The average scores for women and men were 86.6 and 62.4 , respectively. This difference between men and women was especially likely to increase the frequency of women's widowhood; $48.6 \%$ compared to only $10.5 \%$ among men, as well as the response rate with "never" to items related to sexual desire (item 24) and sexual activity (item 25) (Table 2), which were similar to the widowhood rate of $47.4 \%$ and $49.0 \%$. Moreover, it must be noted that the length of the marital status is the result of women's life expectancy at birth, which is relatively higher than that of men (77.8 years vs. 74.5 years) (HCP, 2018). In addition to that, the age gap between spouses at the time of marriage and the possibility of men remarrying after the death of their spouse is high. For the scales of "social functioning" and "life satisfaction", there was no gender association, which shows the value of this age group without any difference between men and women and the fact that the culture and customs of the Moroccan society towards these people reinforce social ties which consequently leads 
to supporting them as well as their integration into the society, as people who are wise, and experienced, in addition to that as people who have effectively fulfilled their roles in society.

Moreover, the results showed that the quality of life of participants and all their scales deteriorated with age. In fact, regardless of the dependent variable, the average score would significantly increase with age. This is still the biggest differentiator of aging and has a great impact on its quality. Similarly, the level of education, which is one of the most important factors that determine personal living conditions and health status (better access to information related to health education, nutrition and life hygiene), also seemed to affect the quality of life of elderly participants' scale. The positive impact of intellectual activities on the quality of life of the elderly has been fully demonstrated; compared with peers with a higher education level, illiterate or less educated people suffer more damage (Martin, 2010). Consequently, education has a great influence on the cognitive performance of older participants. This effect seems to be reflected in the lower allocation of dedicated resources required to perform certain tasks (Guerrero-Sastoque, Bouazzaoui, Burger, \& Taconnat, 2017). However, the level of education was assumed to be closely related to the average age of people with secondary education and above. The average age was 69.2 years $(=4.4)$, while the average ages of elementary school and illiterate counterparts were 70.2 years $(6.3)$ and 72.2 years (7.0), which showed a statistically significant difference (Kruskal-Wallis $\mathrm{H}=7.2 ; \mathrm{p}<0.01$ ). Morbidity also greatly affected the participants' health-related quality of life and various aspects. The physical deterioration (high frequency of chronic pathologies) that older people are expected to face increases with age (Monod-Zorzi et al., 2007; Lalive d'Epinay et al., 2008). Chronically ill participants were statistically older than their unaffected counterparts $(72.3 \pm 7.0$ years vs. $69.7 \pm 5.4$ years; MannWhitney's u-test $=4.2 ; \mathrm{p}<0.001)$. Professional activity is an essential element in an individual's life because it is obvious that any activity with a decent and stable salary would certainly have a positive effect on the individual's living conditions while enabling him or her to meet their daily needs, and to ensure a sufficient and a balanced nutrition, satisfactory living conditions, a better access to health care and a satisfactory social life in general. Any activity in general whether it is professional or nonprofessional, is associated with both physical and mental health. Socio-professional activities are statistically related to the participants' socioeconomic level, as well as to the participants' quality of life and all test scales, i.e. the Depression-Anxiety Scale (Kivits, Erpelding, \& Guillemin, 2013).

Nowadays, living to old age and not being able to work exposes individuals without pensions to severe economic insecurity this can only be addressed through special solidarity (mostly family solidarity). There is no doubt that the family environment will have positive impact on the lifestyle, the health state and the quality of life of the elderly, and the cohabitation will also contribute to intraand inter-generational family solidarity, with children providing care and kindness to their parents at all stages of their lives and especially in old age. Therefore, the family is the most important social institution that can meet the needs of the elderly. In fact, family members, especially children, will provide elderly parents with all the financial means to meet their daily needs, especially for those who cannot benefit from any type of social or medical insurance, which is the case for the majority of elderly Moroccans. In addition, children will provide parents with psychological, emotional and physical support, especially in vulnerable and/or dependent situations (HCP, 2006; Baali et al., 2012; Baali et al., 2017). Similar to the education level and morbidity, age is also a confounding factor that may affect the impact of social and professional activities on the quality of life of the studied samples. Therefore, the subjects who declared they had never had a socio-professional activity and the retirees were older than the participants who are still practicing a professional activity was of 71.7 years $(\sigma=7.2), 7.9$ years $(\sigma=6.3)$ and 69.3 years respectively $(\sigma=4.1)$ (Kruskal-Wallis $H$ test=8.9; $p<0.01)$. However, this only affected the scales of "physical function", "care", "cognitive function" and "life satisfaction". Studies have shown that negative perceptions of aging have many effects on physical health (Levy, 2000). In addition, older participants tend to have a negative perception about the future and tend to be unsatisfied about their life (Netuveli, Wiggins, Hildon, Montgomery, \& Blane, 2006). However, in our case, age had nothing to do with the perception of age: participants who perceived 
old age negatively were on average at the same age as their counterparts who had a positive view, which was demonstrated in the result $70.9(=6.3)$, and $71.8(=6.8)$ years old (Mann-Withney utest $=1.01 ; \mathrm{p}=0.29)$. Similarly, there were no associations between this variable, morbidity and the level of education.

\section{Conclusions}

The overall quality of life of Moroccan people over 65 and living at home was satisfactory. However, the results showed that variables such as "sexual function", "physical function" and the selected socio-demographic characteristics (gender, age, education level, occupational activity, morbidity and perception of age) have a negative effect on the quality of life of the participants. Based on the Moroccan socio-economic and cultural background, implementing programs for this age group, focusing on preventing the consequences and effects of chronic diseases, preventing vulnerability and dependence, good social integration and physical and intellectual maintenance activities, as well as the professionalization of certain occupations, the improvement of the medical and financial care, and the assistance to the most disadvantaged families are very necessary to ensure that the elderly could enjoy a good "quality of life" in the years to come.

Conflict of interest: None

\section{Acknowledgments}

The authors sincerely thank all those who were deliberately involved in the investigation and, consequently, the realization of this work. Also special thanks go to the Health Authority of Marrakesh.

\section{Funding} this article.

The authors received no financial support for the research, authorship, and/or publication of 


\section{References}

1. Baali A., Elkharouai E., Amor H, Elkhoudri N., Manoussi A., \& Ouzennou N., (2017). Sujet âgé et solidarité familiale: étude d'un groupe de personnes âgées marocaines, [Elderly subject and family solidarity: study of a group of Moroccan elderly people] Séminaire international, Vieillissement de la population et solidarités en Afrique : regards croisés, Journées GDRI Vieillissement en Afrique (GDRI VA) - Tours, France 1-2 décembre 2017 [International Seminar, Population Ageing and Solidarity in Africa: Cross-Looking, GDRI Ageing Days in Africa (GDRI VA)- Tours, France 1-2 December 2017].

2. Baali, A., Lahmam, A., Amor, H., Aboussad, A., Boestch, G., \& Chapuis-Lucciani, N. (2012). Perception du vieillissement, état de santé et environnement socio-démographique d'un groupe de personnes âgées (Marrakech, Maroc). [Perception of ageing, state of health and socio-demographic environment of a group of older people (Marrakech, Morocco)]. Antropo, 27, 105-111.

3. Bruin, A. Picavet, H. S. J, Nossikov, A., \& World Health Organization. Regional Office for Europe. (1996). Health interview surveys: towards international harmonization of methods and instruments / edited by A. de Bruin, H. S. J. Picavet \& A. Nossikov. Copenhagen: WHO Reg. Publ. Eur. Ser. 58, 1-161. Retrived April 23, 2021 from https://apps.who.int/iris/handle/10665/107328.

4. Compagnone, P. D., Van M. T., \& Bouisson, J. (2007). Definition of the quality of life by elderly. European Review of Applied Psychology-Revue, 57(3), 175-182.

5. De Leo, D., Diekstra, R. F., Lonnqvist, J., Trabucchi, M., Cleiren, M., Frisoni, G. Della Buono, M., Haltunen, A., Zucchetto, M., Rozzini, R., Grigoletto, F., \& Sampaio-Faria, J. (1998, LEIPAD). An internationally applicable instrument to assess quality of life in the elderly, Behavioral Medicine, 24, 17-27. doi: 10.1080/08964289809596377.

6. Elkafssaoui, S., Boufares, A. Kesouati, J., Bouaiti, E., Mrabet, M., \& Arara, A. (2017). Epidémiologie de malades chroniques suivis à l'hôpital militaire d'instruction Mohamed V de Rabat, Maroc. [Epidemiology of chronic patients followed at the military hospital of instruction Mohamed V in Rabat, Morocco]. Revue d'Épidémiologie et de Santé Publique, 65, Suppl. 2, S96.

7. Grafeille, N. (2016). Sexualité de la femme âgée. [Sexuality of the elderly woman]. In: Trivalle $\mathrm{C}$, editor. Gérontologie préventive. Eléments de prévention du vieillissement pathologique. [Preventive gerontology. Elements to Prevent Pathological Aging] English version here] 3ed Paris: Masson, 521-34.

8. Graziottin, A., \& Leiblum, S. R. (2005). Biological and psychosocial pathophysiology of female sexual dysfunction during the menopausal transition. J Sex Med, 2, 133-45. doi: 10.1111/j.1743-6109.2005.00129.x.

9. Guerrero-Sastoque, L., Bouazzaoui, B., Burger, L., \& Taconnat, L. (2017). Effet du niveau d'études sur les performances en mémoire épisodique chez des adultes âgés : rôle médiateur de la métamémoire. [Educational level effect on episodic memory performance in older adults: Mediating role of metamemory]. Psychologie française. https://doi.org/10.1016/j.psfr.2017.05.002.

10. Jalenques, I., Auclair, C., Roblin, J., Morand, D., Tourtauchaux, R., May, R., Vaille-Perret, E., Watts, J. Gerbaud, L., \& De Leo, D. (2013). Cross-cultural evaluation of the French version of the LEIPAD, a health-related quality of life instrument for use in the elderly living at home. Quality of Life Research, 22(3), 509-520. doi: 10.1007/s11136-012-0166-y.

11. Jalenques, I., Auclair, C., Rondepierre, F., Gerbaud, L., Tourtauchaux, R. (2015). Healthrelated quality of life evaluation of elderly aged 65 years and over living at home. Rev Epidemiol Santé Publique, 63, 183-190. doi: 10.1016/j.respe.2015.02.024. 
12. Kharrat, O., Mersni, E., Guebsi, O., Ben Salah, F. Z., \& Dziri, C. (2017). Quality of life and elderly people in Tunisia. NPG Neurologie - Psychiatrie - Gériatrie, 7, 5-11.

13. Kivits, J., Erpelding, M. L., \& Guillemin, F. (2013). Social determinants of health-related quality of life. Rev Epidemiol Santé Publique, 61, Suppl. 3, 189-94. doi: 10.1016/j.respz.2013.06.001.

14. Lalive d'Epinay, C. Guilley, E., Guillet, L. A., \& Spini, D. (2008). The Swiss Interdisciplinary Longitudinal Study on the Oldest-Old: Design and population. In The Closing Chapters of Long Lives. Results from the 10-Year Swilsoo Study on the Oldest Old. New York, USA: Nova Science Publishers, Inc., 9-26. doi: 10.1007/978-981-287-080-3_244-1

15. Levy, B. (2000). Handwriting as a reflexion of aging self-stereotypes, Journal of Geriatric Psychiatry, 33, 81-94.

16. Martin, N. (2010). Fonctions adaptatives chez les sujets âgés: influence des processus de comparaisons sociales, temporelles et des réminiscences [Adaptive functions of the elderly: Effect of the processes of social, temporal comparisons and of the reminiscences]. Neurol Psychiatr Geriatr, 10, 149-53. doi: 10.1016/j.npg.2010.06.001

17. Monod-Zorzi, S., Seematter-Bagnoud, L., Büla, C., Pellegrini, S. \& Jaccard, R. H. (2007). Maladies chroniques et dépendance fonctionnelle des personnes âgées. Données épidémiologiques et économiques de la littérature. [Chronic diseases and functional dependence of the elderly. Epidemiological and economic data in the literature]. Retrieved April 23, 2021 from https://serval.unil.ch/resource/serval:BIB_40442A802703.P001/REF.pdf

18. Netuveli, G., Wiggins, R. D, Hildon, Z., Montgomery S. M., \& Blane D. (2006). Quality of life at older ages: evidence from the English longitudinal study of aging. J. Epidemiol Community Health, 60, 357-63. doi: 10.1136/jech.2005.040071.

19. Rada, C. (2020). The quality of life when approaching retirement and during retirement in Romania. How important are age, marital status, communication and satisfaction within the family? Revista de Psihologie, 66(2), 97-111.

20. Thomas, P., \& Hazif-Thomas, C. (2008). Les nouvelles approches de la dépression de la personne âgée. [New approaches to depression in the elderly]. Gérontologie et société 2008/3, 31(126), 141 - 155. doi: 10.3917/gs.1260141.

21. ***ACAPS (Autorité de Contrôle des Assurances et de la Prévoyance Sociale) [Insurance and Social Welfare Control Authority]. (2017), Rapport annuel secteur de la prévoyance sociale. [Annual report of the social security sector]. Ministère de l'Economie et des Finances [Ministry of Economy and Finance], Rabat, Morocco.

22. ***ANAM (Agence Nationale de l'Assurance Maladie) [National Agency for Health Insurance]. (2016). Rapport d'activités de l'Agence Nationale de l'Assurance Maladie. [Activity report of the National Health Insurance Agency]. Marocco.

23. ***HCP (Haut-Commissariat au Plan) [High Commission for Planning]. (2017). Projections de la population et des ménages 2014-2050. [Projections of population and household 20142050]. Centre d'Etudes et de Recherches Démographiques (CERED), [Center of demographic studies and researches], Rabat, Marocco.

24. ***HCP (Haut-Commissariat au Plan) [High Commission for Planning]. (2006). Personnes âgées au Maroc: Situation et perspectives. [Elderly people in Morocco: Situation and prospects]. Centre d'Etudes et de Recherches Démographiques, [Center of demographic studies and researches], Rabat, Marocco.

25. ***HCP (Haut-commissariat au Plan) [High Commission for Planning], 2018. Indicateurs sociaux [Social indicators]. Direction de la Statistique [Directorate of Statistics], Morocco, $311 \mathrm{p}$. 
26. ***ONDH (Observatoire National du développement Humain) [National Observatory for Human Development], 2015. Situation des personnes âgées au Maroc. [Situation of the elderly in Morocco]. Retrieved April 23, 2021 from https://www.ondh.ma/sites/default/files/documents/_rapport_personnes_agees_1.pdf

27. ***United Nations (2019). World Population Ageing 2019: Highlights (ST/ESA/SER.A/430). $\quad$ Retrieved April 23, 2021 from https://www.un.org/en/development/desa/population/publications/pdf/ageing/WorldPopulati onAgeing2019-Highlights.pdf

28. ***WHO (World Health Organization). (1999). Division of Health Promotion, Education, and Communication. Glossaire de la promotion de la santé.[Glossary of health promotion]. $\begin{array}{llll}\text { Retrieved April } & 23, & 2021 & \text { from }\end{array}$ https://apps.who.int/iris/bitstream/handle/10665/67245/WHO_HPR_HEP_98.1_fre.pdf?sequ ence $=1 \&$ isAllowed $=\mathrm{y}$ 